\title{
Code-Switching as a Multilingual Strategy in Conversations among Indonesian Graduate Students in the US
}

\author{
Ani Pujiastuti \\ Islamic University of Indonesia
}

\begin{abstract}
Choosing what language to use and what cultural values to adopt may be problematic for international students undertaking cross-border studies in the U.S. This problem occurs simply because the students bring with them the various cultural values and beliefs, and language-related identities with them in a new linguistic environment. This paper aims at identifying the major patterns of language use among Indonesian students in the U.S. and the reasons of Indonesian students in choosing particular languages in conversations.

The study involved eighteen Indonesian students undertaking master and doctoral studies in some American universities. The survey and interview methods are used to gather the data. The results of the survey and interview disprove my previous prediction that the inter- or intrapersonal mechanism, such as community or institutional norms, accommodation, politeness, physical condition such as fatigue or laziness, and rationality may determine the speakers' language choices. This study indicated that that Indonesians in the U.S. might be aware of the importance of influences such as, cultural values that may directly or indirectly impact the language preference, and some unpredictable and violable arrangements for language choice, such as exclusion/inclusion of others in addition to the apparent communal perception of English as the accepted institutional and social password in the U.S. Additionally, I learned that the students' multilingual strategy was reflected in their ability to 'play safe' in using the languages in multilingual interactions, by selecting the most comfortable languages in conversations without neglecting others who were within their earshot.
\end{abstract}

Keywords: codeswitching, language choice, multilingualism, graduate students in the US 


\section{Introduction}

On summer trip in 2007, on the way to Baltimore, one of my Indonesian friends could not help but finishing up his sentence in Javanese when commenting on our American travel mate sloppily washing his hands using our 'precious' mineral water. $\mathrm{He}$ said, "Why don't you wait till we stop at the hotel to wash your hands? It's 'eman-emain', you know!" Then he continued grumbling in Javanese. I assumed that his alternation from English to Javanese was simply due to the absence of the English word for 'emaneman', which actually means 'something that needs to be saved and cared about because of its preciousness.' Since I travelled 'with Indonesians who have different regional language backgrounds, I was wondering at that time why he used Javanese instead of the Indonesian (Bahasa Indonesia) terms and sentences, considering that the later is described as "the language of wider communication among those of different ethnolinguistic backgrounds (Lowenberg, 1992, p. 66). Even though we traveled in the same van and ate at the same dining.table during the trip, it seemed that our togetherness was often separated by language barriers. Since we always wanted to use codes that were most comfortable for us, we tended to use our regional language (Javanese) and native language (colloquial Bahasa Indonesia) throughout the trip. Language conflicts and misunderstanding sometimes occurred due to the linguistic preferences we made. As a consequence, our American travel mates complained about our language crossing behavior since they were within our earshot. They thought that we did that on purpose to exclude them from conversations, or gossiped about them behind their backs. Although we admitted that they might be right to a certain extent, we actually used our native languages for several other reasons such as to show solidarity, even though; borrowing Blom and Gumperz' terms of solidarity and non-solidarity to conversants (2000), this might mean that we violated our solidarity with our American travel mates, and cover up the absence of particular terms in English. Besides, fatigue or tiredness also sometimes forced us to use a shortcut to Indonesian and neglect the American ears. I realized that when we spoke our language in a multilingual setting, we might forget that we have indirectly silenced others. Therefore, whether it is negative or positive, our American friends' reactions towards our language crossing behavior reminded us to be aware of the communal norms governing language use in foreign settings. Specifically, this experience in language contact generated questions in my mind related to the typical features of language use among Indonesian students in the U.S., and their reasons for choosing a particular language in conversation in foreign settings.

During the last twenty years there has been a sharp boost in the efforts of the Indonesian government to send students and scholars abroad. Considering the unbeatable status of English as an international language, the Indonesian government still prioritizes English speaking countries as the study destination to send those creams of the crops in the Indonesian academic field. In order to academically survive in a foreign environment, students have to make sure that their linguistic performance meets the academic as well as social requirements. Since most of Indonesian students are naturally bilinguals with at least two languages, it is assumed that shifts of social norms governing 
their language use may happen when they live in foreign settings. Goebel (2002a) suggests that discussing the social norms influencing the language choice should be placed : under the same umbrella of exploring the factors : affecting speakers' communicative competence. Since students' communicative competence is among the most important factors in determining their academic and social achievements, the phenomenon of students' language use in multilingual settings has triggered some interest in research focused on language contact, which normally involves bilingual and multilingual speakers, and language choice resulting from the language contact activities.

When engaging in language contact activities, Indonesian students may have to adapt to the new communal norms in the U.S., which includes the language. Because of the existing different norms, a misunderstanding resulting from the language crossing activities may occur especially when the students are interacting in multilingual settings. Without denying the fact that language crossing activities may perform a multilingual competence for speakers, it is worth noting that "the ability to code-switch may sometimes be regarded with suspicion or disfavor in certain circumstances by English speakers"(Wardhaugh, 2002, p. 107). Following Wardhaugh, I assume that my American friends' complaints during the summer trip may show the monolingual speakers' critical reactions towards the new forms resulted from code-switching activities. Considering that code-switching may play a significant role in Indonesian students' linguistic activities in the U.S., research on this matter is necessary.

\section{Previous Research on Code-Switching among Indonesians}

The rich array of regional languages and ethnic groups in Indonesia has provided material studies on language contacts among different groups of speakers. Several research studies on language contacts have been conducted involving speakers from the same ethno- linguistic backgrounds in Indonesia, such as a study on Javanese speakers' code-choices in East Java by Wolff and Poedjosoedarmo (1982); Errington's (1988) research on language use among priyayi (urban nobility) in Solo, Central Java; Martin's (2005) study on language shifts and code-switching in Northern Borneo. The research on code-switching involving speakers from different ethnicities has challenged researchers such as Zurbuchen (1984) who studied the interactions between Balinese and nonBalinese and Wolff and Poedjosoedarmo ( 1982) who explored the use of regional languages among Indonesians. Despite of the abundance of research on code-switching conducted on interethnic groups in Indonesia, however; apparently there is a limited research on code-switching inyolving Indonesian students staying in foreign countries, except for Tanner (1967); Yassi (2001) and Novera (2004). As cited in Wardhaugh (2001), Tanner's study was focused on linguistic usage of a small group of JavaneseIndonesian graduate students and their family members in the U.S. in 1967. His study reported that "Indonesians in the U.S. tended to use English when discussing academic topics, but Bahasa Indonesia for most other common activities." An interesting finding in that study was the assumption that Bahasa Indonesia was regarded as a "neutral and democratic" language, while Javanese was only used with closed intimates to express respect among the speakers, related to age and status difference (as cited in Wardhaugh, 
2001, p. 101). Considering the unstable political situation of Indonesia in 1960's, it was apparent that Bahasa Indonesia was mostly used to show a sense of political nationality. To my knowledge, and it was in fact noted by previous research on interethnic codeswitching among Indonesians (see e.g. Wolff and Poedjosoedarmo, 1982 and Zurbuchen, 1984), it should be understood that whenever they are outside the country, JavaneseIndonesians want to be identified as Indonesians and not Javanese. Tanner's approach on analyzing code-switching from a sociolinguistics perspective opened wider doors for research in the same area. Yassi.(2001) conducted another study on code-switching studies from a different point of view. Relying on data collected from pengajian (Islamic teaching) activities among students in an Australian university; Yassi mapped the typical patterns of Indonesian-English code-switching based on their syntactic categories, combinability of switched segments and types of code-switching. Without denying its significant contribution toward studies on the struggle of Indonesian students abroad, the most recent research conducted by Novera (2004) does not directly touch the language use, since it is focused more on academic, cultural and social experiences of Indonesian students in Australia.

Recent research studies on code-switching involving speakers from different ethnicities are pioneered by Goebel (2002a). Relying on data taken from two neighborhoods in Semarang, Central Java, she undertakes a geographically oriented linguistic study of intra-ethnic and interethnic interaction in those two communities that consisted of speakers from different ethnicities. Acknowledging her debt to previous researchers such as Wolf and Pedjosoedarmo (1982); Zurbuchen (1984), she agreed to some points that Bahasa Daerah (regional languages) were sometimes used in interethnic interaction to indicate familiarity" (p. 70). Goebel noted that this finding was different from generalizations made by some other researchers in the previous decade, that Bahasa Indonesia is the language used in wider communication involving speakers from different ethnicities (see, e.g. Lowenberg, 1992 and Nababan, 1991). Challenged by those different arguments, Goebel conducted a deeper research study by presenting code-switching activities in interethnic and foreigner-Indonesian interactions. In this research, she blended the discussion on language switching with some pedagogical implications on the teaching and learning of English in Indonesia, (2002b). Driven by her serious concerns on language education in Indonesia, collaborating with Black (see, Black \& Goebel 2001, 2002), Goebel conducted another research study by discussing the neglected area in the teaching of Indonesian, namely the social significance of Indonesian varieties with regard to regional languages. In this research, the two authors also proposed the application of a multimedia teaching tool as a possible solution, and discussed how this relates to the multiliteracies approach to pedagogy.

Another study involving interethnic interactions was conducted by Martin (2005), discussing language shift and code-switching in Northern Borneo and how languages of wider communication, both Malay and.English, affect the language use in Kuala Belait, Northern Borneo. The multiracial condition in Indonesia has challenged more researchers to explore language use by different ethnicities. Wolff (1997) and 
Rafferty (1984), for example, explored the language use among Chinese immigrants in Indonesia. Wolff particularly analyzed the speech and identity of Peranakan Chinese (mixed Chinese-Indonesian) in Java. The term Peranakan was used to identify a person with mixed blood, and during the. Dutch colonial times, this term referred to anyone of mixed racial ancestry. It should be noted that Chinese-Indonesian are not native speakers. of the Chinese language anymore, instead, they created their own language based on the regional language (Javanese), colloquial Indonesian and Dutch. Since they created their own language, Peranakan Chinese constructed their own identity to distinguish them from the pribumi (Javanese origins). The study on code-switching among Peranakan Chinese conducted earlier by Rafferty presented the language of Chinese in Java, how those speakers experienced a language loss and adopted low Malay and regional language (Javanese) as a means of communication among themselves.

The phenomena of language contact may be approached from-diverse perspectives, and it provides a wide area to be explored. I found one study on language choice among an Indonesian religious group (Muslim) which was focused on the use of Javanese, Arabic and Indonesian in conversations (Susanto, 2006): Relying on the data taken from religious musyawarah (religious meeting), the author reported that the participants' reason for code-switching was mostly driven by metaphorical factors, e.g., Arabic phrases were inserted in conversation and speech in order to gain religious merits.

Despite the abundance of research on code-switching among intra-ethnic and interethnic Indonesian speakers, a very limited number of studies were done on language choice among Indonesian students abroad, particularly in the U.S. The lack of information on this matter has led me to undertake a study of language choice as a multilingual strategy among Indonesian graduate students in the U.S. This study is aimed at analyzing the language preference and the reason for choosing particular languages on particular occasions. As Indonesian students share the same language (Bahasa Indonesia), and sometimes regional languages (depending on their ethnicities), it is assumed that the students have more than one linguistic code that they can alternate as a resource of linguistic strategy during conversation.

\section{The Status of English in Indonesia}

Regardless of the significant use of English in Indonesia, the status of English in this country is still that of a foreign language. English is one of the subjects taught in most government-sponsored high schools. French and German are alternative foreign languages, but the majority of the students choose English. Students who choose English are exposed to two to four hours of English instruction a week throughout their six years . of high school. Besides these traditional government schools, there are a number of private and government-sponsored schools, such as bilingual schools and immersion programs, in which the medium of instruction for most subjects is English. Some of these have primary school sections where the instruction in English begins as early as the first or second year. Enrollment in these schools is very selective, based on entrance exam scores. 
- Furthermore, there are also many state and private universities which offer English-medium education at degree levels, which is called the international program (college level) or the immersion program (secondary level). Admittance to these programs and schools are by the central university or school entrance examinations. Such universities and schools offer intensive preparatory English classes, which are normally conducted in the first year, for those students who do not have adequate proficiency to follow classes which are conducted completely in English.

Considering these educational circumstances, therefore, more and more people in Indonesia'are aware of the fact that, at least some knowledge of English is necessary to get ahead in life. It brings high status to the individual socially, as well as extending job opportunities. Consequently, many parents do their best to have their children educated in an English school. Because of the extensive English use in some vital fields in Indonesia, parents also send their children to some private English courses, or if they are wealthy enough, to foreign countries.

The development and use of English in Indonesia may be as fast as the spread of MacDonalds and Starbucks, which can now be found on every corner of the cities in this country. Just as the existence of 'MacDonaldization' there is also a trend to 'Englishify' some aspects of Indonesian people's lives such as the entertainment industry, which touches people's everyday's lives in general.

In everyday conversation, to begin with, English expressions are used as a conversation smoother by combining them with colloquial.Indonesian, such as 'So what gitu loh?' (so what?), 'Please deh!' (for crying out loud!), and so on. This creativity in using English-flavored expressions is especially used by youngsters, and they will be considered old-fashioned if they do not follow this trend. This fact, I guess, has inspired some people in the entertainment industry to apply this trend in movies, TV shows and music. In the movies, for example, there is a trend to insert English flavor both in title and dialogue, such as in 'Love is Cinta', 'Eiffel, I'm in Love', 'Heart', 'Virgin' and 'Me and High Heel' as well as in songs such as 'Heart', 'You and Me' and 'Welcome to My Paradise'. There are also popular bands that adopt English-like names such as 'God Bless', 'Sheila on Seven', 'Slank', 'Steven and the Coconut Tree' and so on.

There is also a trend for TV stations to air English programs, ranging from news to reality shows. These programs have not only fueled the use of English, but also increase the desire of Indonesians to equip themselves with the ability to understand English.

\section{Regional Languages (Native Languages) of Indonesia}

Hudak reported that "with a population of more than 200 million, Indonesia is the home of hundreds of minority languages" (1998). I personally believe that the diversity of languages, cultures, religions and traditional beliefs has made Indonesia a sociolinguistically fascinating country. It is considered common to speak two or three languages as one shuttles from one speech community to another, even though they have Bahasa Indonesia as the national language. Indonesian's national language is a 
standardized dialect of the Malay language that was officially defined with the declaration of Indonesia's independence in 1945, and reformed spelling was proposed in 1972 (Nababan, 1991). Bahasa Indonesia is used as a medium of instruction in every school, aside from the regional languages or vernaculars. Since students also have to take English and/or other foreign languages at schools, bilingualism, and even multilingualism is quite common for Indonesians. Nababan reported that government, through the ministers of education centrally established the curriculum used in schools. The curriculum which is applied in standard syllabus for a course book is pragmatic and communicative and it is also equally applies to foreign languages (1991).

Indonesia is the fourth most populous nation in the world. Of its large population the number of people who fluently speak Bahasa Indonesia is fast approaching $100 \%$, thus making Indonesian one of the most widely spoken languages in the world. Most Indonesians, aside from speaking the national language, are often fluent in another regional language or local dialect (for example, Javanese, Minangkabau, Balinese and Sundanese and so on) which are commonly used at home and within the local community. Most formal education, as well as nearly all national media and other forms of communication, are conducted in Bahasa Indonesia.

Furthermore, Bahasa Indonesia is a normative form of the Malay language, an Austronesian language which has been used as a lingua franca in the Indonesian archipelago for centuries. Because of its origins, Indonesian (in its most standard form) may sometimes be mutually intelligible with the official Malaysian language. However, it does differ from Malaysian in some aspects, with differences in pronunciation and vocabulary.

Bahasa Indonesia and some regional languages have been influenced by other languages along with the mobility of people that will require them to understand each others' languages. Borrowing terms from other languages is not a rare phenomenon. Based on the linguistic diversity in Indonesia, then, Indonesians are encouraged to codeswitch the languages in communication with others. Specifically, in order to linguistically survive in a foreign or new setting, students may need to adapt to different communal norms governing the language use.

\section{Code-Switching among Bilinguals and Multilinguals}

Whenever people speak, in whatever languages and styles they use, they make choices. Being able to alternate from using one language to another may well reveal one's linguistic intelligence. Coulmas (2006) stated that "the ability to consider alternatives and opt for one is basic to intelligent life." There has been a significant trend among researchers to approach the language crossing behavior from various perspectives. Nevertheless, it seems that the existing theories of code-switching have been almost exclusively based on research in communities characterized by relatively stable bilingual or multilingual speakers living in particular regions, such as previous research conducted on Spanish communities in the U.S., French in Canada, Arabic in Britain or other 
immigrants all over the world. In her study involving bilingual speakers in an academic department in a U.S. university, Weninger (2007) pointed out that the previous influential theories on code-switching were all characterized by different views toward approaching and explaining code-switching. Since those studies were mainly focused on stable speakers from particular groups or communities, such as immigrants. and permanent residents, it is assumed that the researchers may pay more attention to the large issues such as speakers'shared normative systems and their participation in and interpretation of social interactions. Weninger's study tried to open a wider scope of approaching codeswitching from a different point of view, involving bilingual speakers from two different language backgrounds (Spanish and German). She touched other aspects influencing speakers' language choices such as motivation and ethnic identity. As Romaine (1994) reminded us, other more personal issues related to code-switching, such as motivation and various pressures from background differences in economy, culture, administration, politics, religion, etc. may need to be taken into account.

From the sociolinguist's point of view, code-switching is studied to understand why people who are competent in two languages or more alternate languages in a particular situation or conversation (Reyes, 2004). The concept of code-switching, as defined by Gumperz (as cited in Reyes, 2004, p. 78), refers to "the altemate use of two or more languages in the same utterance or conversation, or a situation in which a speaker (or a writer) uses a mixture of distinct language varieties as discourse proceeds." Therefore, it does not only refer to the situation when two or more speakers switch to different languages in conversation, but also when they use different varieties or styles. Furthermore, Skiba (1997) gives an additional explanation that choices about how codeswitching manifests itself are determined by a number of social and linguistic factors. Accordingly, code-switching and the other types of language choices might be quite typical in bilingual, multilingual and immigrant populations. Code-switching, as Gal (1988 as cited in Wardhaugh, 2002,P. 100) puts it, carries a deeper meaning since it may perform "a conversational strategy used to establish, cross or destroy group boundaries; to create, evoke or change interpersonal relations with their rights and obligations."

Instilled by their rights and obligations in using particular languages, speakers code-switch based on various reasons. The illustration in the earlier part of this paper supports Crystal's (1987) argument that the first reason for code-switching is the speaker's limited knowledge of a particular language; therefore, alternation to another language is needed to cover up the speaking deficiency. As a result, the speaker may speak another language for a certain amount of time. This type of code-switching tends to occur when the speaker is upset, tired or distracted in some manner. The second reason, according to Crystal, commonly occurs when an individual wishes to express solidarity with a particular group. Relationship and understanding is established between the speaker and the listener when the listener responds with a similar switch. Additionally, this type of switching may also be used to exclude others who do not speak the same language from certain topics discussed in conversations. Such a situation can be found, for example, in an English speaking environment, when there are two people on a bus, 
sharing the same native language, speaking in a language other than English. They may choose to talk in their language intentionally because of the sensitivity of conversation topics that requires them to be cautious of not offending others: Others on that bus, who do not speak the same language, would be excluded from the conversation and a degree of comfort would exist amongst the speakers in the knowledge that not all those present on the bus are listening to their conversation. Crystal also contends that another reason for code-switching is that the alteration occurs when the speaker wishes to convey his/her attitude to the listener, such as admiration, disagreement, or even anger. Where monolingual speakers can communicate these attitudes by means of variation in the level of formality in their speech, bilingual speakers can convey the same by code-switching. Further, Crystal suggests that where two bilingual speakers are accustomed to conversing in a particular language, switching to the other is bound to create a special effect (1987). These notions suggest that code-switching may be used as a socio-linguistic tool by bilingual speakers.

Additionally, when people mix the formal and informal styles,. it can also be discussed under the umbrella of code-switching. In fact to my knowledge, I believe that, while bilinguals and monolinguals code-switch, monolinguals may do the same thing with particular codes in their languages, for example the use of slang by American youngsters, honorifics by Javanese speakers, Bahasa gaul' used by Indonesian youngsters. In fact, code-switching can take place in a conversation when one speaker uses one language and the other speakers answer in different languages. So a person may start speaking one language and then change to another one in the middle of their speeches, or sometimes even in the middle of a sentence, based on the functions of their conversations. Apparently, Grosjean highlights an interesting phenomenon where multicompetent users have the ability to alternate between languages when speaking with people sharing the same languages (1989). He provides a further explanation that there will be a possibility for multicompetent users to not only use two or more languages separately, but they may also use those languages at the same time. As a consequence, code-switching may occur in various patterns. Grosjean's argument was based on Spolsky's (1998) categorization of code-switching, i.e. intersentential switching, when speakers switch from one language to another at a sentence boundary, and intrasentential switching, or code-mixing when the switch takes place within one sentence.

Following Spolsky, Blom and Gumperz (2000) introduce two patterns of codeswitching based on factors affecting it. They assert that code-switching varies according to the situation (situational code-switching) and within a conversation (metaphorical code-switching). Under the metaphorical category, code-switching varies according to discourse functions. In some situations, code-switching is done deliberately such as to

1. Bahasa gaul is the informal Indonesian "language of sociability", commonly used among Indonesian university students and in various publications aimed at middle-class Indonesian youth. This language expresses not only young people's aspirations for social and economic mobility, but also increasingly cosmopolitan, national youth culture'(Heffner, 2007). 
include or exclude someone from a conversation, to convey intimacy, or to emphasize a message. Thus, it may be seen as a sign of solidarity within speakers who share the same language and non-solidarity when they mean to exclude particular speakers outside the group. In other words, speakers switch languages to achieve a special communicative effect. Previously, Gumperz (1982) has developed the above concepts of code-switching and introduced another term, conversational code-switching, which includes functions such as quotations, addressee specification, interjection, duplication, message qualification and personalization. In this case, Gumperz stresses the importance of discourse in code-switching, giving clues about conversational contributions such as assurance of the message conveyed and change of topic in conversations.

Another study related to the social functions of code-switching from a socialpolitical perspective is seen in a study by Heller (1992), who highlights that codeswitching in general may be used as a political strategy, especially in ethnic mobilizations. In her view, and in order to understand the role and significance of codeswitching in a given community, it is essential to understand not only its distribution in such a community but also how that distribution is attached to the way groups control both the distribution of access to valued resources, such as jobs and social mobility, and the ways in which that value is assigned. In this case, Heller points out how sociopolitical factors seem to influence the actual presence or absence of code-switching in a given community. Speakers may want to present particular identities attached in the languages used, and accordingly, whether they are driven by an emergence or existed social norms, the motivations for code-switching may always change.

Myers-Scotton (1985) developed the above situational and metaphorical dichotomy and presents the Markedness Model (MM) which is based on the notions of social motivations for code-switching. According to Myers-Scotton, language choice might be related to identity construction. Therefore, if a speaker's language choice is unexpected or marked in a given situation, it redefines the role relations and situations. By using two or more linguistic varieties in the same conversation, speakers may negotiate a change in the social distance between themselves and other participants in the conversation. In other words, speakers may always have desires to present particular. identities or wish others to view themselves attached to particular identities through the languages they use.

\section{Significance of the Study}

This study aims to explore how Indonesian university graduate students in the United States demonstrate their multilingual competencies through the use of codeswitching among English, Bahasa Indonesia and their regional languages in conversations both in monolingual and in multilingual settings. . I would like to highlight that the concept of code-switching refers to the alternate use of two or more languages in the same utterance or conversation, or a situation in which a speaker (or a writer) uses a mixture of distinct language varieties as discourse proceeds. However, this research will only focus on spoken language. This study will also identify the particular patterns of 
language preference and some possible reasons why those students chose a particular language over another language in conversations with their peers in various settings. The term "Indonesian university graduate students" in this study refers to participants who are pursuing degrees (both $\mathrm{MA}$ and $\mathrm{PhD}$ ) in universities in the United States and who share different regional languages and a national language. The Regional language refers to local dialects spoken by Indonesians based on their ethnicities. The native language in this paper refers to Bahasa Indonesia, assuming that every Indonesian students in the U.S. speak this language.

Additionally, this study is also guided by a number of theoretical assumptions related to code-switching and multilingualism. In terms of students' use of code'switching, it was expected that the participants of this study would use relatively the same strategy in communicating among their peers both in public and private situations. This expectation is based on the assumption that they developed the same level of proficiency in English and the same knowledge of grammatical systems of both their native languages and English. According to Poplack (1980), those factors have been found necessary for code-switching to occur. A research conducted by Poplack (1980) indicates that speakers who are fluent and balanced in both languages tend to be better at alternating and switching languages. Therefore, considering that the participants shared the same fluency in both languages, it was also expected that they would have relatively the same reasons in choosing the languages based on the contexts and situations.

The reason to choose Indonesian graduate students was that, even though possessing different regional languages; they understand one common language, which is Bahasa Indonesia. As noted by Coulmas (2006, p. 109), in relation to the phenomena which occur in daily life, L2 speakers living in multilingual communities may always face the reality that they have to choose which language to use. This will result in a condition where people may switch from one language to another, based on their needs and the conditions around them. Code-switching may also be related to some other factors such as motivations driven by social conditions in certain speech communities. In short, code-switching may be used to activate social meanings, maintain solidarity, display preferences and attitudes and conform to the norms in a certain community (Gumperz, 1982;. Myers-Scotton, 1985; Crystal, 1987; Blom \& Gumperz, 2000; Coulmas, 2006).

Despite the great abundance of research on code-switching, little or no research was focused on groups of multilingual speakers sharing different native languages and temporarily staying in particular multilingual communities. Speakers who stay in particular regions within a limited time such as students or temporary workers, may have different reasons for code-switching, resulting from various linguistic interactions. Regardless of the fact that those speakers are engaged in communications within institutional settings that prescribe a particular language to be used within the communities, I-assume that Indonesian students in the U.S. may have particular considerations in choosing what language to use with their peers in both monolingual and 
multilingual settings. Since it is assumed that those students communicate with relatively the same group of people as their communities of practice (academic and nonacademic) during their stay in the U.S., I am particularly interested in investigating the nature of code-switching, the major patterns of code-switching and the reasons for choosing a language over another. I also intend to find out whether the relationship with particular speakers will affect their choice of language in conversation. Since there are limited studies focusing on speakers sharing different native languages and temporarily staying in particular communities, this study is necessary. The students Involved in this study share relatively common language backgrounds; they speak their own native language, Bahasa Indonesia as a national language and English as a foreign language. Since those students speak different native languages, it needs to be noted that there is a possibility that they posses different cultural values based on the languages they speak. For instance, comparable to their cultural values and beliefs, it is apparent that Malay speakers from Sumatra will be more direct in conversation compared to Javanese speakers. Presumably, there may be particular factors governing whether to choose their native language, Bahasa Indonesia or English in conversations with their peers both in monolingual and multilingual settings. Their language preference in Indonesia (within their families or working places) may also reflect their tendency of language choice in communicating with others in the U.S.

In this study, I explored the nature of code-switching among Indonesian university students in the U.S. to gain more a comprehensive understanding on how those students perform their communication strategies in different communities and settings. First, with regard to Gumperz (1982), I assumed that speakers' goals, values and attitudes are necessary factors in analyzing code-switching. Accordingly, mapping the features of code-switching and its realizations became the initial base of this study. I also believed that speakers may have to negotiate some kinds of cultural values both among themselves and with their Americans friends (which may or may not overlap with the U.S. contexts). On the one hand, particular expressions may occur both in English and Bahasa Indonesia (or regional languages). On the other hand, certain codes may be considered as polite/impolite or too sensitive/taboo in either language, which may enable term-switch to occur. For English speakers, it may be common to use the word "dog" to illustrate the sound $/ \mathrm{d} /$, however, for Indonesians, especially Javanese speakers, for Instance, the use of such term is culturally inappropriate, because the . word "dog" (asu=Javanese) is considered as an incredible insult in the Javanese language (Beazley, 2003). Based on those assumptions, it may be interesting to find out how the Indonesian students in the U.S. deal with such complexity, reflecting in how, what and why particular language is chosen. Therefore, the following research questions were formed to guide the study:

1. What are the major patterns of language use among Indonesian students in the U.S.?

2. What are the reasons of Indonesian students in choosing particular languages in conversations? 


\section{Research Methodology}

The study applied both survey and interview methods. Thirty participants were contacted through emails. Then, out of thirty students, eighteen potential participants were selected based on the following considerations:

1. The participants are Indonesian university graduate students in the U.S.

2. The participants should all speak different regional languages from one another (i.e. Javanese, Sundanese, Balinese and Madurese); Bahasa Indonesia as a national language and English as a foreign language.

3. The participants have stayed in the U.S. for more than a year

The reason why I recruited eighteen participants is based on the fact that there are more than 400 regional languages in Indonesia (Nababan, 1991), and the above native languages chosen are in fact the ones that have the greatest number of speakers in Indonesia. This survey method was used to find out the preference of language used in conversation and the reasons of choosing a particular language over another in conversations both in monolingual and multilingual settings. Following the survey, three interview participants were selected based on the survey response. The interview was conducted to elicit specific and elaborative information on the speakers' rationalization on code-switching. The interviews were scheduled for approximately thirty to forty-five minutes for each participant. Since some participants reside in different states in the U.S., other than conducting a face-to-face interview, these activities were also carried out through telephone and/or online messenger chatting. All interviews were audio taped and transcribed for data analysis purposes.

\section{Design and Procedure}

The first stage of data collection, which is the survey activity, was executed by means of surveymonkey program, thus it was conducted online. This process was aimed at assessing the participants' language switching activities and their reasons in choosing a particular language over another in conversations. The advantage of conducting the survey is that, on the one hand, doing so has enabled me to gather data from a large number of participants and, the other hand, to develop a comprehensive view of a particular issue. Additionally, in the effort of revealing the interrelations between different underlying factors and processes influencing individual language choice, I interviewed the participants. I asked the participants to reflect their language choice activities and provide their own explanations, and required them, as individuals, to further explicate their perceptions about their experiences of and conscious or inadvertent choices regarding language preference in more depth than it is possible from the survey alone. Weninger (2007, p. 138) strongly argues that participants of a study should be given "a chance to voice their own understanding about why they do particular things". His idea is criticizing the opinion regarding the "common belief in social science research that the researcher's interpretation of observed behavior is more objective or-accurate than interpretations by those whose behavior is being observed". . Following Darlington 
\& Scott; I think it will also be necessary to be engaged in a more in-depth qualitative study, as this will allow me to "explore questions which relate to the meaning of experiences and to deciphering the complexity of human behavior (2002, p. 3$)$. The interview questions were divided.into two parts. The first part consisted of participantsi linguistic backgrounds (comprising their competence in the languages they spoke), and the second part covered their explanations and rationalizations of choosing a particular language in conversations (see Appendix $\mathrm{D}$ for the interview protocol).

\section{Findings and Discussion}

The data analysis was based on the survey and interview results. Eleven males and seven females participated in the survey. Those students are native speakers of Javanese, Sundanese, Balinese, Madurese, Acehnese, Malay and Batakese, and all of them speak Bahasa Indonesia on a daily basis. Additionally, as multilingual speakers, the participants claimed that they speak at least two or three languages, starting with a native language that they first learn from their parents, Bahasa Indonesia and English, and some additional languages and dialects. Three participants speak more than four languages. As typical Indonesian students in general, most of the participants (96\%) admitted that they started studying English in junior high school. Therefore, all of them also stated that they have been studying English for more than ten years. Since the students are from the same study batch (they came to the U.S. at almost the same time), they have been in the U.S. for relatively the same length time. Accordingly, most of them admitted that since their planes landed in the U.S., they have had to use English on a daily basis.

In the survey, the participants were asked to map their language use in different contexts and conversation partners. For this purpose, the participants' use of the three languages (regional language, Bahasa Indonesia, and English), and the alternations among those languages were addressed in the survey. In regard to the major pattern and rationalization of code-switching, the discussions based on the survey results are categorized as follows:

\section{Mono language-Monolingual Settings}

When engaged in a conversation with students who share the same language backgrounds (Bahasa Indonesia), the students tended to use Bahasa Indonesia. This finding was in accordance with previous studies which stated that Bahasa Indonesia is used among Indonesians from different ethnicities, and to strengthen their sense of . nationality, especially when they are abroad (see, e.g. Wolf and Poedjosoedarmo; 1982; Zurbuchen, 1984). Based on the interview, the three participants seemed to agree on one point why they use Bahasa Indonesia and not English when speaking with Indonesians in the U.S. The primary reason was because they assumed that every Indonesians would understand Bahasa Indonesia. The three interview participants also admitted that using English with Indonesians may show snobbishness, as shown in the following excerpt: 
"I think I use Indonesian because it's...I know all Indonesian speak Indonesian, that's why...so I use Indonesian....and second...okay...I don't want to use English because I don't want the other person to think me as arrogant." (Henny)

Additionally, using English among Indonesians may also create gaps among Indonesians themselves and sometimes it may generate a linguistic conflict. One of the participants whom I interviewed stated that whenever he used English in Indonesian forums, he will be gossiped about as the case of Ijul's below:

Ijul: $\quad$ ntardigosipin lagi

(then, (people) will make a gossip (about me) again)

Ani: $\quad$ ok, got it

Ani: huh?

Ijul: $\quad$ sama orang Indo di sini

(by Indonesian people here) (ljul, my translation)

It is apparent that English was infrequently used in conversation among Indonesians in the U.S., even though one or two words may be inserted in sentences. Crystal's (1987) notion was proven in this study that the reason for inserting English words in conversation was particularly caused by the absence of certain terms in both Indonesian and the regional language. Additionally, I must acknowledge Gumperz (1982) for his comment on the importance of topic of conversations in determining what language to use and whether code-switching may occur during conversation. The following excerpt from the interview with $E k a$ may illustrate the significance of topics in determining what language to use in conversations:

"If the topic is about crap or nonsense we use Bahasa all the time. If we discuss serious stuff, then we normally borrow some English words or even phrases". (Eka)

It is interesting for me how $E k a$ inserted the term "crap" in his sentence. Even though this may be far away from my discussion on code-switching, $E k a$ 's choice of words has inspired me to conduct another additional research on this matter. I wonder if Crystal's (1987) idea that the speaker's mental or physical conditions such as tiredness, upset feeling or another mental distraction has something to do with this. I may connect this discussion with Gibbons' (1997), findings in his research involving university students from Hong Kong. He indicates that the challenge for the students (Chinese) is not learning new vocabulary items. Students may recognize the meaning or sense of particular words when they know that people use them and then they imitate their actions. Thus, instead of translating the words that do not exist in their native language, they tend to insert the words in conversation whenever they need them. Accordingly, I assume that $E k a$ inserted the word "crap" because he noticed people around him using this term in conversation.

It was surprising that the use of English only in conversation was relatively higher than that of native language (Bahasa Indonesia). This finding somewhat violated the assumption that Bahasa Indonesia (see previous notes by Wolff \& Poedjosoedarmo, 
1982; Zurbuchen, 1984; Goebel, 2002a) may function as glue sticking for Indonesian speakers since they share the same language. This assumption is also based on the understanding that when Indonesian students live abroad, they may want to build their nationalism by insisting that they will speak their native language among themselves. The use of Bahasa Indonesia among Indonesians to deemphasize the great difference in languages (and cultures) may be reflected through the nation's motto, "bhinneka tunggal ika" ${ }^{2}$ which means "unity in diversity" (Nababan, 1991; Sneddon, 2003; Allen, 2005). For this particular reason, it must be understood that the use of regional language (assuming that Indonesians speak different regional language based on their ethnicities), may violate the spirit of "unity in diversity". Accordingly, despite its sense of intimacy or closeness, when used in a foreign setting, regional languages may be considered as having a divisive influence towards the speakers. This finding is also in accordance with Heller's (2002) idea that code-switching may perform some kind of political strategy. When mobilizing to new places, speakers choose a particular language for a certain reason related to their ethnic identity. The following table illustrates the language preference in monolingual settings. Each language is used among Indonesians when they mingle in a group consisting of only Indonesians in the U.S.

Table 1. Mono language in monolingual settings

\begin{tabular}{|l|l|l|}
\hline Language & Frequency of language use & Percentage \\
\hline Regional language & Low & 7 \\
\hline Bahasa Indonesia & High & 65 \\
\hline English & Average & 28 \\
\hline
\end{tabular}

\section{Mono language-Multilingual settings}

When engaged in conversations in multilingual settings or public places in the U.S., the students' language preference seemed to change accordingly. English was likely to dominate the language preferred. The students' choice of language in foreign settings, as noted by Weninger (2007) may show their metapragmatic awareness of their language use, which is tailored to their language preference. As Verschueren puts it, metapragmatic awareness which "performs a crucial force behind the meaninggenerating capacity of language in use refers to indirect signaling within the stream of discourse or the constant ability of speakers to perform self-monitoring in speaking and interpreting others' talk $(2004$, p. 36$)$. By possessing metapragmatic awareness, Verschueren claims that speakers must understand what they are doing when they use a particular language. A speaker's metapragmatic awareness is illustrated by the following excerpt taken from Verschueren's (2004: 68): 
$\mathrm{N}$ : If it is granted to us

G: Inshallah, inshallah, inshallah

N: Eh? But in the mosque I did not see you?

G: That's where I am going right now!

The above conversation is about a soccer game that they are going to watch the next day. In order to express the nature of humans' inability to control the future course of events, $\mathrm{N}$ uses a conditional statement, "If it is granted to us". In a Muslim's way G's respond to $\mathrm{N}$ by using the Arabic term, "inshallah" (if God wishes). G's response which reflects a Muslim identity tap's N's metapragmatic awareness so he changes the topic about G's absence in the mosque. In his next response, G shows his acceptance to N's switch of topic.

When they are communicating with peers sharing the same language, and acknowledging that there are speakers of other languages, they choose a language which can be understood by both parties. Therefore, there is some kind of negotiation of preference versus accommodation, with relatively diverse motivations for both. In addition, a lack of interaction involving the native language (e.g. in the coffee shop) may mean that the desire to accommodate others, with each comprising motivations has propelled the students to use English, which is the dominant language spoken in the U.S. Table 2 illustrates the use of mono language in multilingual settings or public places.

Table 2. Mono language in multilingual settings

\begin{tabular}{|l|l|l|}
\hline Language & Frequency of language use & Percentage \\
\hline Regional language & Low & 28 \\
\hline Bahasa Indonesia & Average & 18 \\
\hline English & High & 54 \\
\hline
\end{tabular}

\section{Multi language-Monolingual Settings}

The code-switching that occurs in conversation between Indonesians in monolingual settings was primarily involving Bahasa Indonesia and English. I am indebted to Heller's (2002) idea about the possibility of code-switching to represent power of the users. I also agree with Fasold that, when communicating in foreign settings, speakers may build their sense of nationalism through language, as well as culture (2001, p. 3). The language used by Indonesians in the U.S. then may be categorized as the low variety (in this case, Bahasa Indonesia) and English as the high variety, considering that it is the dominant language in the American setting. From table 3. it can be seen that the combination of Bahasa Indonesia and English was most preferable for students. This illustration was also in accordance with the generalization previously made by Wolf and Poedjosoedarmo (1982) and Zurbuchen (1984) about the use of Bahasa Indonesia in interethnic communications: However, the fact that the use of English (along with 
Bahasa Indonesia) surprised me considering that in the interview the participants admitted that they restricted the use of English among.Indonesian peers to avoid showing arrogance.

Table 3. Multi language in monolingual settings

\begin{tabular}{|l|l|l|}
\hline Language & Frequency of language use & Percentage \\
\hline Bahasa Indonesia and English & Average & 47 \\
\hline Bahasa Indonesia and regional language & Low & 16 \\
\hline Regional language and English & Low & 18. \\
\hline $\begin{array}{l}\text { Bahasa Indonesia, regional language and } \\
\text { English }\end{array}$ & Low & 19 \\
\hline
\end{tabular}

\section{Multi language-Multilingual Settings}

Even though the previous pair of Bahasa Indonesia still occurred in high frequency of use, there is a significant difference between code-switching in monolingual and multilingual settings. Since the students communicated in multilingual settings, I assumed that the communal norms might influence the language use. Related to the notion of power in language use and sense of nationality (Heller, 2002; Fasold, 2001), by using Bahasa Indonesia along with English in multilingual settings, the students' wanted to strengthen their sense of nationality among Indonesians, while at the same time, obeying the communal norms in the American culture. The students' metapragmatic awareness was also showed by their low frequency in using languages that were only understood among Indonesians. In this case, it might also reflect the students' solidarity toward English speakers. As illustrated by the following table, when communicating in the 'English-dominating' environment, students tend to blend English and Bahasa Indonesia more frequently:

Table 4. Multi language in multilingual settings

\begin{tabular}{|l|l|l|}
\hline Language & Frequency of language use & Percentage \\
\hline Bahasa Indonesia and English & High & 78 \\
\hline Bahasa Indonesia and regional language & Low & 8 \\
\hline Regional language and English & Low & 4 \\
\hline $\begin{array}{l}\text { Bahasa Indonesia, regional language and } \\
\text { English }\end{array}$ & Low & 10 \\
\hline
\end{tabular}

\section{Rationalizations of Code-Switching.}

From the survey, most of the participants, surprisingly, admitted that the reasons for language switching were driven by their linguistic deficiency resulting from the unavailability of particular terms in the languages involved. Beside supporting Crystal's (1987) idea about the common rationalization of code-switching, this finding was also in line with Gibbons' (1997) research study on Chinese students, related to their tendency to 
switch their languages, instead of struggling with translations for particular terms which may be missing in a language. In the case of Indonesian students, it was apparent that some students might claim particular terms and built their new communal norms when they interacted in multilingual settings in the U.S. The use of academic terms (when they discussed academic topics) and swear words (when they were upset or angry) by the students, for instance, showed their reluctance use translation, although those terms were also available in their languages (see, e.g., $E k a$, one of the interviewees used the term "crap" instead of its Indonesian or Balinese translation). Considering their status as multilinguals, prior to departing to the U.S., Indonesian students have been familiar with language crossing behavior. For them, choosing which terms to use in conversation may take the benefits of knowing other terms from other languages. In Indonesian settings, when Bahasa Indonesia became the high variety (versus the regional languages as the low varieties), speakers also have tendencies to apply the terms used in Bahasa Indonesia when discussing particular matters, instead of translating them into regional language terms. Although students may take advantage of being multilinguals, they did not consider themselves as having an exclusive status. It was shown in the survey that most participants were strongly against the idea of using code-switching actions to show pride, or request for acknowledgement from others of their being exclusively multilingual or distinguished. Even in initiating what language to use among peers, the participants admitted that they never initiate the choice; instead, regardless of the settings and contexts of speaking, they tended to follow the stream of how language is used in the conversations. The following interview excerpt illustrates how the participants decide to use a particular language:

"I didn't think okay...I have to speak English...not like that...and it's like he always replies to me in Indonesian or Javanese and if that's going on for a while so I understand it...okay... he doesn't want to speak English, I need to speak to switch to Indonesian...okay".(Henny)

Following Verschueren (2004), I assume that the speakers' metapragmatic competence does not always mean that they have to always take the lead in conversations by deciding what language to use or what topic to talk about. As seen in the above illustration, the ability of speakers to manage conversation flows seemed to be more important, since it might have reflected their understanding of what codes were used.

Some students noted that they sometimes switch their languages on purpose in order to prevent others from understanding what they were talking about. Again, topic might play a central role in determining what languages to use. Switching languages based on topics selection usually it happens when speakers want to exclude people who are not directly part of the conversation, but are within earshot. Interestingly, based on the survey and supported by one of the interview participants, some speakers addressed this issue from the flip side by choosing the non-dominant language (either Bahasa Indonesia or the regional language) in order to allow the bystanders to understand what is being discussed. He switched the language in order to invite the bystanders' attention or 
curiosity about what was being discussed. When they were interested in the discussion, then, these speakers might provide further explanation (and sometimes translation) so as to enable the bystanders to understand the topics being discussed. In fact to my knowledge, it might also show the speaker' multilingual strategy in conversation, by letting others not sharing the same language involved in the discussion. When this happens, it might mean that the sense of solidarity may not only be addressed to peers sharing the same language, but also to bystanders. Four participants explained that one of the reasons for code-switching was influenced by their physical or psychological conditions. When they are tired or stressed, they admitted that their tongues became 'lazier' which hinders them from using translation strategy. In this case, in accordance to Weninger's (2007) research study, the language last spoken among participants may also determine the language chosen in the subsequent conversation flow.

The relations among conversants also seemed to play important roles in determining what language to use. The closeness among participants may also determine what language to use, in this case, for example, the regional language may serve as a mediator in a heated discussion. One of the interview participants reported that he used Bahasa Indonesia to accommodate conflict, as shown in the following excerpt:

“...soalnya banyak konflikdi Indonesian community sini

(because (there are) a lot of conflicts within the Indonesian community (here)." (Ijul, my translation)

He admitted that the use of English or inserting English phrases in conversation may heat up a discussion. It was understandable, considering that English is considered as the high variety in the U.S. community. Whenever a speaker initiates the use of English in monolingual discussions among Indonesians, he/she may violate the solidarity stance. The speakers' rationalizations for code-switching can be seen in the following table:

Table 5. Rationalizations for codeswitching

\begin{tabular}{|l|l|}
\hline Reported Rationalizations for code-switching & percentage \\
\hline Expressing solidarity & 33 \\
\hline Exclusion/inclusion of bystanders & 19 \\
\hline Unavailability of relevant vocabulary & 35 \\
\hline Physical/psychological state & 7 \\
\hline Showing pride & 3 \\
\hline
\end{tabular}

2. Bhinneka tunggal ika (originated from Sanskrit) is the motto of the Republic of Indonesia that acknowledges the multiethnic and multilingual nature of Indonesia and emphasizes the importance of unity. 


\section{Domains influencing code-switching activities}

The importance of conversation domains was first introduced by Fishman (1975, as cited in Weninger, 2007). Then, relying on a questionnaire on domain-analysis, Greenfield and Parasher (in Fasold, 2001) conducted research involving Spanish bilingual speakers in New York City. The result showed that the relationship among speakers, conversation topic and participants performed the high domains determining the language preference.' Surprisingly, from the survey, it was shown that the topic of conversation was chosen as the highest factor influencing code-switching. It seems that Indonesian students consider that the topic may determine how they sense a language. The following excerpts, for instance, show how a particular language is more preferable:

1. "But if we are like...eating...and we are talking about...I don't know...like... what is our favorite television show or something like that... Javanese"(Henny).

2. “...especially if we want to critique something...I think...like I want to criticize, for example my dean about the school policy or something like that...I feel much much better using English"(Henny).

The following table illustrates the-influence of conversation domains in determining the language choice by Indonesian students in the U.S.

\begin{tabular}{|l|l|}
\hline Domains & percentage \\
\hline Degree of relationship among conversant & 18 \\
\hline Conversation topic & 55.6 \\
\hline Location & 11 \\
\hline Participants & 16 \\
\hline
\end{tabular}

It was apparent that the students' language choice was influenced by both stable factors such as topic, participants and locations, and situational or emergent factors such as the physical conditions and moods. Those factors interchangeably provided an array factors in selecting which languages or codes to use. Sometimes, speakers' language acts were performed intentionally and in some other occasions, their choices were not the results of rational deliberation, especially when speakers were engaged in conversations in multilingual settings. Again, based on motivations, goals, conversation topics, participants and contexts of speaking may result in particular patterns of code-switching which may characterize the speakers' multilingual strategies in multilingual settings. However, I believe that those patterns may be subject to change due to the dynamisms of interactions 


\section{Implications}

I previously predicted that that there will be no or little structural, inter- or intrapersonal mechanism, such as community or institutional norms, accommodation, politeness, physical condition such as fatigue or laziness, and rationality that may singularly : account for speakers' language choices, although each of them may be involved. As I am myself multilingual, based on my personal experience, I assume that there will be other possible factors driving language choice for international graduate students in the U.S. First, related to the result of the survey and interview, I would say that Indonesians in the U.S. might be aware of the importance of other. influences such as, cultural values that may directly or indirectly impact the language preference, and some unpredictable and violable arrangements for language choice, such as exclusion/inclusion of others in addition to the apparent communal perception of English as the accepted institutional and social password in the U.S. Interestingly, the students' multilingual strategy was reflected in their ability to 'play safe' in using the languages in multilingual interactions. They selected the most comfortable languages in conversations without neglecting others who were within their earshot.: Borrowing Verschueren's (2004) term, metapragmatic awareness, what I mean by 'playing safe' in using the language is that, the students' code-switching activities were not only meant to express solidarity among Indonesians but also to other International students and Americans. Second, the Indonesian students' attitudes (which was not directly discussed but implicitly included in this paper) towards their culture and the languages they speak may as well impact the language choice activities. The latter is based on the idea that, when using a particular language, those students may have particular sense, taste or meaning, attached to their cultural values and beliefs. This assumption was particularly gathered from the in-depth interview process.

As I stressed in the methodology section, a joint investigation of language data from a survey and speakers opinions is likely to provide a better illustration of codeswitching activities. However, other unpredictable aspects may be generated if the researchers use different methods. Therefore, if this to be done again for the future research, it would be beneficial to apply another method such as speech diary, where speakers are asked to record their language preference over a longer period of time. Based on the natural function of a diary to picture activities and experiences, this may enable the participants to provide more accurate data since obviously they will have more freedom in talking about themselves compared to when they are videotaped in an interview. Norton contends that the entries generated from speech diary may "highlight the relationship between the social interaction and social identity" $(1994$, p. 25). Hence, since being engaged in social interactions.may require the participants to code-switch, this technique can benefit the researcher and participants in providing supplementary and authentic data. 


\section{References}

Allen, P. M. (2005). Deconstructing the diaspora: The construction of ChineseIndonesian identity in post-Suharto Indonesia. In: Asian Futures, Asian 'Traditions, Global oriental. UK: Folkestone, 128-139.

Beazley, H. (2003). The construction and protection of individual and collective identities by street children and youth in Indonesia. Children, Youth and environment, 13,(1).

Black, P. \& Goebel, Z. (2001). Multiliteracies and the teaching of Indonesian. Babel, The Journal of the Australian Modern Languages Teaching Association, 37, (1), 2226.

Coulmas, F. (2006). Sociolinguistics: The study of speaker's choices. Cambridge: Cambridge University Press.

Darlington, Y. \& Scott, D. (2000). Qualitative research in practice. Buckingham: Open University Press.

Errington J.J. (1998). Shifting languages: Interaction and identities in Javanese Indonesia. Cambridge: Cambridge University Press.

Gibbons, J. (1997). Code mixing and code choice. A Hongkong case study. Clevedon: Multilingual Matters.

Goebel, Z. (2007). Enregisterment and appropriation in Javanese-Indonesian bilingual talk. Language in Society, 36, 511-531. Cambridge: Cambridge University Press.

Goebel, Z. (2002a). Code choice in interethnic interactions in two urban neighborhoods of Central Java, Indonesia. International Journal of Sociolinguistics and Language, 158, 69-87.

Goebel, Z: (2002b). When do Indonesians speak Indonesians? Some evidence from inter-ethnic and foreigner-Indonesian interactions and its pedagogic implications. Journal of Multilingual and Multicultural Development, 23, (6), 479-489.

Grosjean, F. (1982). Life with two languages: An introduction to bilingualism. Massachusetts: Harvard University. Press.

Gumperz, J.J.(1982). Discourse strategies. New York: Cambridge Úniversity Press.

Gumperz, J.J., \& Berendz, N. (1993). Transcribing Conversational Exchanges. In J.A. Edwards \&.M.D. Lampert (eds.), Talking Data (91-122). Hilldale, NJ: Lawrence ErlbaumAssociates. 
Fasold, R. (2001). The sociolinguistics of society. Massachusetts: Blackwell Publishers Inc.

Heller, M. (1992). The Politics of Code-switching and Language Choice. Journal of Multilingual and Multicultural Developmet, 13, 123-42.'

Hudak, T.J. (1998). ' (Review of the book Shifting languages: Interaction and identities in Javanese Indonesia). Johnstone, B. (2000). Qualitative methods in sociolinguistics. New York: Oxford University Press.

Lowenberg, P.H. (1992). Language and Identity in Indonesia. Journal of Asian Pacific Communication 3, (1), 59-77.

Martin, P. (2005). Language shift and code-mixing: A case study from Northern Borneo. Australian Journal of Linguistics, 25, (1), 109-125.

Myers-Scotton, C. (1988). Code switching as indexical of social negotiations. In M. Heller (eds.) Codeswitching. Anthropological and Sociolinguistic Perspectives, 151-186. Berlin: Gruyter.

Myers-Scotton, C. (1988). A theoretical introduction to the Markedness Model. In C. Myers-Scotton (ed.) Codes and Consequences. Choosing Linguistic Varieties, 18-38. New York: Oxford University Press.

Myers-Scotton, C. (1993). Social Motivations for Code-switching: Evidence from Africa, New York: Oxford University Press.

Nababan, P.W.J. (1991). Language in education: the case of Indonesia. International Review of education. Internationale Zeitschrift Fur Erziehungswissenschaft. Revue Internationale De Pedagogie, 37, (1), 113-131.

Novera, I. A. (2004). Indonesian postgraduate students studying in Australia: an examination of their academic, social and cultural experiences. International Education Journal, 5, (4), 475-487.

Peirce, B. N. (1994). Using diaries in second language research and teaching. English Quarterly, 26,(3).

Poplack, S. (1980). Sometimes I'll Start a Sentence in English y termino en espanol: Toward a Typology of Code-switching. Linguistics, 18, 581-616.

Romaine, S. (1994). Language in Society: An Introduction to Sociolinguistics. Oxford: Oxford University Press.

Reyes, Illiana. (1994) Functions of Code-switching in Schoolchildren's Conversations. Billingual Research Journal, 28: 1 Spring 2004.

Romaine, S. (1995) Billingualism (2nd ed.). Oxford, England: Blackwell. 
Skiba, R. (2000). Code Switching as a Countenance of Language Interference. Retrieved March 12, 2008 from http:/www.iteslj.org/articles/Skiba-codeSwitching:html.

Smith-Hefner, N.J. (2007). Youth Language, Gaul Sociability, and the New Indonesian Middle Class. Journal of Linguistic Anthropology 17, (2), 184-203.

Sneddon, J. (2003). The Indonesian Language: Its history and role in modern society. Sydney: UNSW Press.

Spolsky, B. (1998). Sociolinguistics. Oxford: Oxford University Press.

Susanto, D. (2006). Code-switching in Islamic religious discourse: The role of Insha Allah. Proceedings of the second Annual Rhizomes: Re-visioning Boundaries Conference of the School of Languages and Comparative Cultural Studies (Queensland, Australia, 24-25 February 2006). Brisbane: The University of Queensland.

Wardhaugh, R. (2002). An introduction to sociolinguistics. Massachusetts: Blackwell Publishers Inc.

Wolff, J.U. (1997). Peranakan Chinese speech and identity. Language and Media,.64, 29-44.

Wolff, J.U. \& Poedjosoedarmo, S. (1982). Communicative codes in Central Java. New York: Comell University Southeast Așia Program.

Yassi, A. H. (2001). (Indolish (Indonesian-English): Toward a typology of IndonesianEnglish code-switching (Electronic Version). Analisis, Jurnal Ilmiah Pasca Sarjana UNHAS, 2, (4). 235-252.

Zurbuchen, M. (1984). Contexts and choices: spoken Indonesian in.Bali. In Aesthetic Tradition and Culture Transition in Java and Bali, A. Morgan and L.J. Sears (eds.), 247-266. Madison: University of Wisconsin, Center for Southeast Asian Studies. 